International Journal of Current Advanced Research

ISSN: O: 2319-6475, ISSN: P: 2319 - 6505, Impact Factor: SJIF: 5.995

Available Online at www.journalijcar.org

Volume 6; Issue 3; March 2017; Page No. 2840-2843

DOI: http://dx.doi.org/10.24327/ijcar.2017.2343.0121

Research Article

\title{
SOME STUDIES ON INVESTIGATING THE CONCEPT OF DETERMINE THE COEFFICIENT OF DISCHARGE FOR TRIANGULAR \& RECTANGULAR NOTCHES WITH THE VARIATION OF DEPTH OF WATER
}

\author{
Shubham Sharma ${ }^{1}$ and Shalab Sharma ${ }^{2}$ \\ ${ }^{1}$ Mechanical Engineering D.A.V University Jalandhar Punjab, India \\ 2Mechanical Engineering CT Institute of Technology, Jalandhar Punjab, India
}

\section{A R T I C L E I N F O}

Article History:

Received $15^{\text {th }}$ December, 2016

Received in revised form $24^{\text {th }}$ January, 2017

Accepted $14^{\text {th }}$ February, 2017

Published online $28^{\text {th }}$ March, 2017

Key words:

Coefficient discharge, end contraction,

rectangular notch, velocity approach, V-notch.

\begin{abstract}
A B S T R A C T
Now a days in modern industries and open channel very precise and accurate notches are used to measure the rate of flow for large and small flow. Notches are classified according to shape, in this experimental investigation different types of notches are used to measure the coefficient of discharge at different rate of flow. Experimental investigation shows that geometry of notches widely affect the discharge co-efficient. A notches of triangular $\left(45^{\circ} \&\right.$ $60^{\circ}$ ) and rectangular are used in this investigation and compare the results of both to find the best notch.
\end{abstract}

Copyright $@ 2017$ Shubham Sharma and Shalab Sharma. This is an open access article distributed under the Creative Commons Attribution License, which permits unrestricted use, distribution, and reproduction in any medium, provided the original work is properly cited.

\section{INTRODUCTION}

To measuring the flow of liquids in different channels and tanks, various types of notches are used. Today in modern era of engineering, different types of notches are used for measuring the flow rate in different channels and tanks. Conventional trapezoidal, rectangular and inverted triangular notches having different angle $\left(45^{\circ}, 60^{\circ}, 90^{\circ}\right.$ most commonly) among the oldest notches. The triangular notches are most commonly devices used for measuring the flow of liquids in open channel. Due to its simplicity in design and calculations. Proper care should be taken while measuring the readings. $1 \%$ of error in the measurement may produce $2.5 \%$ error in result. In this paper experiment are conducted on three types of notches .i.e. "V"notches $\left(60^{\circ} \& 45^{0}\right)$ and rectangular notches. Due to high accuracy at low flow triangular notches are preferred over the rectangular notches.

\section{LITERATURE REVIEW}

Keshava Murthy and Giridhar [1] have proposed the use of Inverted V-Notch (IVN) for flow measurement for nearly 72 $\%$ of the depth of IVN within a prefixed permissible error of $\pm 1.5 \%$. They developed two optimization procedures to obtain the linear head-discharge relationship through the notches. Using the same optimization procedures, they improved the linearity range by introducing rectangular notches at an optimum height over the IVN.

*Corresponding author: Shubham Sharma

Mechanical Engineering D.A.V University Jalandhar

Punjab, India proportionality range for any sharp crested notches to develop any type of head-discharge relationship. Subsequently, the same authors presented a general algebraic optimization procedure to obtain the linear characteristics of inverted semicircular notches [4].

James Thomson, Professor of Civil Engineering at Queens College, Belfast, Ireland, was among the earliest experimental investigators of the triangular-notch notches (Thomson, 1858, 1861). The experiment is conducted at a pond in open field. The purpose of investigation was to achieve the experimental evidence to support his proposal that, for the measurement of discharge included a very small flow the triangular notches are used instead of rectangular notches. Professor Thomson's experimental equipment was crude by modern standards, and the range of conditions covered by his experiments was small. Experiment is James Thomson, Professor of Civil Engineering at Queens College, Belfast, Ireland, was among the earliest experimental investigators of the triangular-notch notches (Thomson, 1858, 1861).the experiment is conducted at a pond in open field. The purpose of investigation was to achieve the experimental evidence to support his proposal that, for the measurement of discharge included a very small flow the triangular notches are used instead of rectangular notches. Professor Thomson's experimental equipment was crude by modern standards, and the range of conditions covered by his experiments was small. Experiment is conducted on two types of "V" notches i.e. $90^{\circ} \& 127^{0}$ where the discharge co-efficient is taken as the $0.593 \& 0.617$ respectively. The result is calculated as for a smaller flow two 
or more $90^{\circ}$ angle notches are used instead of a single large notch angle.

\section{Experimental Setup}

This apparatus consist of a sump tank, pump to circulate water and a flow channel. A set of three sharp edged notch plates made of brass is provided e.g. rectangular and "V" notch having angle $45 \AA$ and $60 \AA$. The notches are interchangeable. The pointer is provided to measure the height of water level over the crust of notch. The discharge through notches can be measured by measuring tank and stop watch. The experiment was performed for different flow rate to measure the co -efficient of discharge.

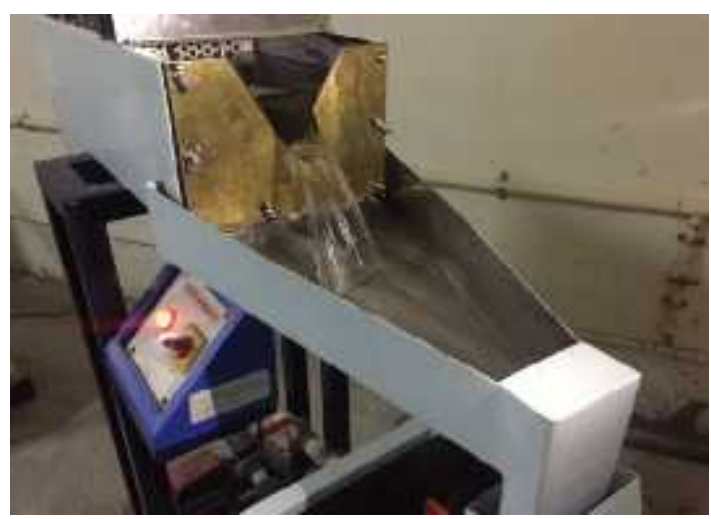

Fig 1 Experimental setup

The equipment consists of a supply tank. Three rows of perforated sheets are fixed to the upstream side to serve as baffles. When the water flows through the baffles, the oscillation are damped out and a steady and smooth flow is obtained. The front side of the supply tank is provided with provisions for fixing interchangeable notch plates. The complete supply tank is supported on a strong iron stand. A fine hook gauge is fixed on a beam across the channel. The pointer serves the purposes of measuring water surface level. A collecting tank is provided to measure the actual discharge.

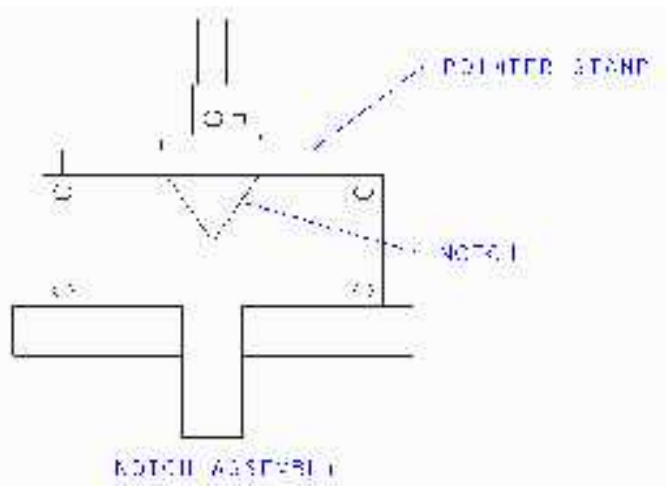

Fig 2 Line diagram of notch setup

Water is supplied to the main channel from water mains through a gate valve that is used to regulate the flow rate. A drain cock is provided at the bottom side of the channel.

\section{ANALYTICAL METHODOLOGY}

The total theoretical discharge over the "V" notch may be found out by the relation given as

$\mathrm{Q}_{\mathrm{T}}=\left(\frac{\mathrm{B}}{\mathrm{L}}\right) \tan \left(\frac{\varnothing}{\mathrm{z}}\right) \times \sqrt{2 \mathrm{~g}} \times(\mathrm{h})^{5 / 2}$
Table 1 Data Table for Test Rig

\begin{tabular}{cc}
\hline \multicolumn{2}{c}{ Apparatus data } \\
\hline Area of measuring tank & $0.077 \mathrm{~m}^{2}$ \\
Channel dimensions & $(0.6 \times 0.25 \times 0.175) \mathrm{m}^{3}$ \\
Triangle notch angle & $45^{0}, 60^{\circ}$ \\
Area of rectangular notch & $(0.102 \times 0.07) \mathrm{m}^{2}$ \\
Electricity supply & $220 \mathrm{~V} \mathrm{AC}, 50 \mathrm{HZ}, 5-15 \mathrm{amp}$ \\
\hline
\end{tabular}

The measurement equivalent discharge passing over v-notch opens as follows:

$\mathrm{Q}_{\mathrm{A}}=$ Area of Tank $\times\left(\frac{\mathrm{D}}{\mathrm{T}}\right)$

Equivalent discharge passing over a rectangular open as follows:

$\mathrm{Q}_{\mathrm{T} .}=\left(\frac{2}{3}\right) \times \mathrm{L} \times \sqrt{2 g} \times(\mathrm{H})^{3 / 2}$

Francis formula for the rectangular notch is given as following:

$\mathrm{Q}_{\mathrm{T} .}=\left(\frac{2}{3}\right) \times \mathrm{L} \times \sqrt{2 \mathrm{~g}} \times\left[\left(\mathrm{H}+\mathrm{h}_{\mathrm{a}}\right)^{3 / 2}-\mathrm{h}_{\mathrm{a}}{ }^{3 / 2}\right]$

Velocity approach of any rectangular notch can be calculated as following:

$\mathrm{Q}_{\mathrm{T} .}=\frac{2}{\mathrm{3}} \times \sqrt{2 \mathrm{~g}}(\mathrm{~L}-0.1 \mathrm{nH}) \mathrm{H}^{3 / 2}$

Where;

$\mathrm{QA}=$ Actual flow rate $(\mathrm{m} 3 / \mathrm{s})$.

$\mathrm{QT}=$ Theoretical flow rate $(\mathrm{m} 3 / \mathrm{s})$.

$\mathrm{Va}=$ Actual velocity $(\mathrm{m} / \mathrm{s})$.

$\mathrm{g}=$ acceleration due to gravity $(\mathrm{m} / \mathrm{s} 2)$.

$\theta=$ angle of V-Notch (varies).

$\mathrm{L}=$ width of Rectangular Weir (m).

\section{RESULT AND DISCUSSION}

Table 2 Variation of coefficient of discharge of rectangular notch with the flow rate

\begin{tabular}{ccccccc}
\hline S.NO & $\mathbf{H}$ & $\begin{array}{c}\mathbf{Q}_{\mathbf{A}} \\
\left(\mathbf{x} \mathbf{1 0}^{-4}\right)\end{array}$ & $\begin{array}{c}\mathbf{Q}_{\mathbf{T}} \\
(\mathbf{x ~ 1 0})\end{array}$ & $\mathbf{C}_{\mathbf{d}}$ & $\begin{array}{c}\mathbf{Q}_{\mathbf{T} . f r a n c i s} \\
(\mathbf{x 1 0})\end{array}$ & $\mathbf{C}_{\mathbf{d}}$ \\
\hline 1 & 3.2 & 7.53 & 11.83 & .63 & 10.75 & .70 \\
2 & 2.8 & 6.13 & 9.68 & .63 & 8.91 & .68 \\
3 & 2.4 & 4.79 & 7.68 & .62 & 7.15 & .66 \\
4 & 2 & 3.91 & 5.84 & .66 & 5.51 & .71 \\
5 & 1.6 & 2.96 & 4.18 & .70 & 3.94 & .75 \\
6 & 1.1 & 1.84 & 2.38 & .77 & 2.30 & .79 \\
7 & .8 & 1.27 & 1.47 & .86 & 1.44 & .88 \\
8 & .5 & .624 & 0.73 & .85 & 7.20 & .89 \\
\hline
\end{tabular}

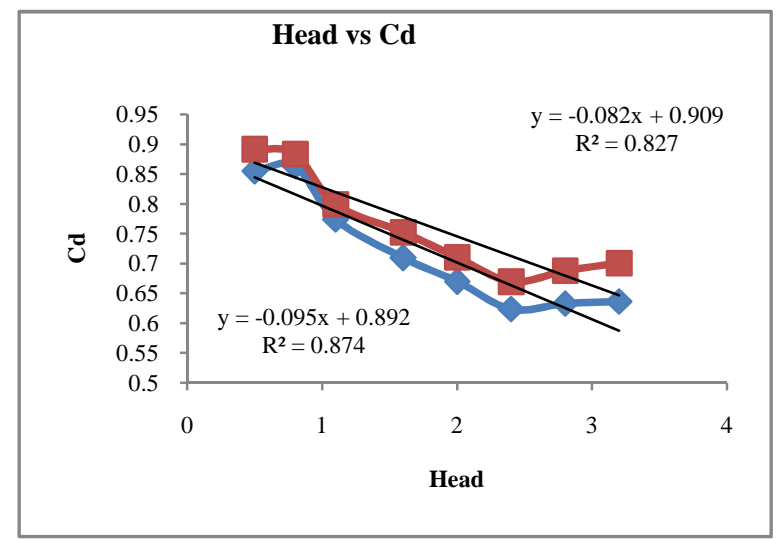

Fig 3 Variation of coefficient of discharge of rectangular notch with head. 


\section{Some studies on investigating the concept of determine the coefficient of discharge for triangular \& rectangular notches with The variation of depth of water}

Fig.3 shows that, at the starting the coefficient of discharge (normal) is linearly raising with the increment of head, with continuously increasing in the head (h). The coefficient of discharge (normal) is sharply decreased. But nearly to the slightly more than the half of total head the coefficient of discharge is linearly increase. The Francis formula provides a better effective result of coefficient of discharge as compare to the normal result because fluid follows the contour rather than state flow due to cohesive force of molecules. This calculation is investigated that the both value of coefficient of discharge is moved parallel.

Table 3 Variation of coefficient of discharge of rectangular notch with the flow rate (with velocity approach)

\begin{tabular}{cccccc}
\hline S.No & $\mathbf{H}$ & $\begin{array}{c}\mathbf{Q}_{\mathbf{A}} \\
(\mathbf{x ~ 1 0})\end{array}$ & $\mathbf{H}_{\text {francis }}$ & $\mathbf{Q}_{\mathbf{T}}\left(\mathbf{x ~ 1 0} \mathbf{1 0}^{-\mathbf{4}}\right)$ & $\mathbf{C}_{\mathbf{d}}$ \\
\hline 1 & 3.2 & 7.5342 & 11 & 11.853 & 0.64 \\
2 & 2.8 & 6.1306 & 10.6 & 9.6984 & 0.63 \\
3 & 2.4 & 4.7945 & 10.2 & 7.6942 & 0.62 \\
4 & 2 & 3.9166 & 9.8 & 5.8521 & 0.66 \\
5 & 1.6 & 2.9684 & 9.4 & 4.1866 & 0.7089 \\
6 & 1.1 & 1.8465 & 8.9 & 2.3859 & 0.7739 \\
7 & 0.8 & 1.2744 & 8.6 & 1.4796 & 0.8633 \\
8 & 0.5 & 0.6247 & 8.3 & 0.73093 & 0.8547 \\
\hline
\end{tabular}

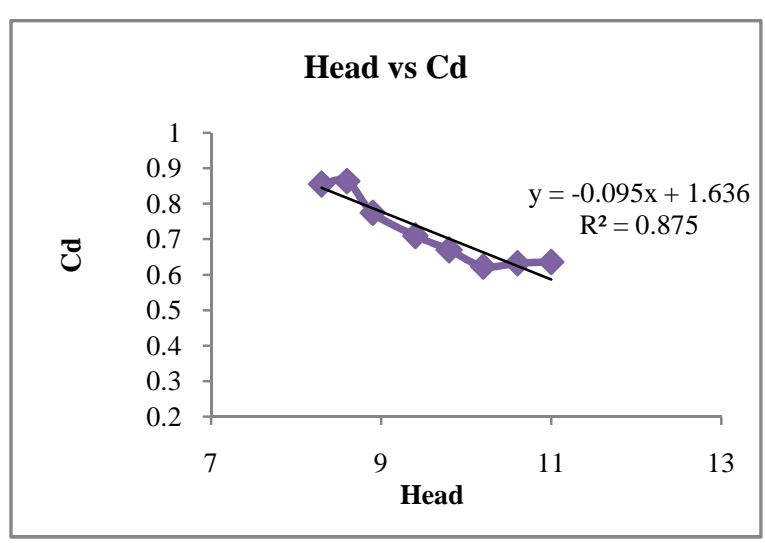

Fig 4 Variation of coefficient of discharge of rectangular notch with head.

Fig.4 shows the variation of coefficient of discharge with the incrimination of head. In the starting the $c_{d}$ starting rising but with the continuously incrimination of head it's going to decreasing uniformly. Similarly as discussion of above nearly to the half of head the cd is again start increasing linearly.

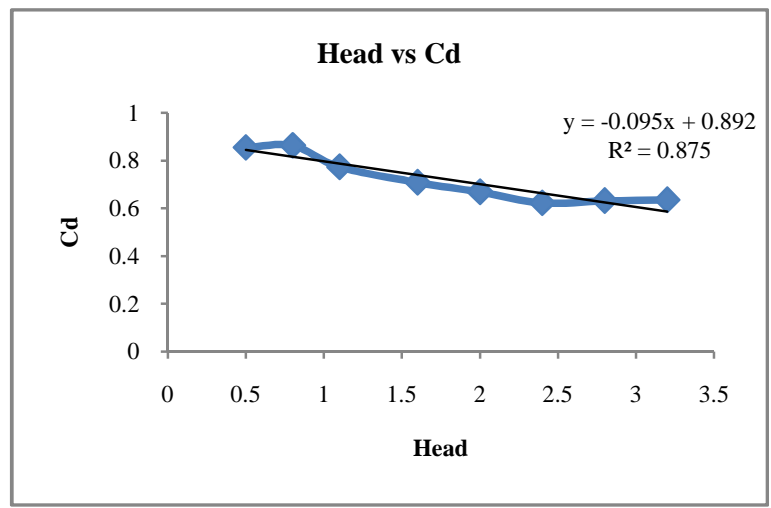

Fig 5 Variation of coefficient of discharge of rectangular notch with velocity approach

Fig. 5 shows that the variation of coefficient of discharge with the extra head due to velocity approach, there is a slight change in the $\mathrm{Cd}$ of rectangular notches. So it indicate that velocity approach factor effect the actual rate of flow in the end of contraction. Given graph shows that at larger flow rate $\mathrm{Cd}$ change is almost negligible i.e. equal to 0.63

\section{Readings of "V" Notches}

Table 4 Variation of coefficient of discharge of V- notch $\left(60^{0}\right)$ with the flow rate

\begin{tabular}{ccccc}
\hline S.No & H & $\begin{array}{c}\mathbf{Q}_{\text {Actual }} \\
\left.\text { (in 10 } \mathbf{1 0}^{-4}\right)\end{array}$ & $\begin{array}{c}\mathbf{Q}_{\text {Theo. }} \\
\text { (in 10 }\end{array}$ & $\mathbf{C}_{\mathbf{d}}$ \\
\hline 1 & 5.6 & 7.0902 & 10.122 & 0.7004 \\
2 & 5.1 & 6.3847 & 8.0115 & 0.7669 \\
3 & 4.3 & 4.0740 & 5.2295 & 0.7790 \\
4 & 3.6 & 2.6570 & 3.3538 & 0.7922 \\
5 & 2.8 & 1.4419 & 1.7893 & 0.8058 \\
\hline
\end{tabular}

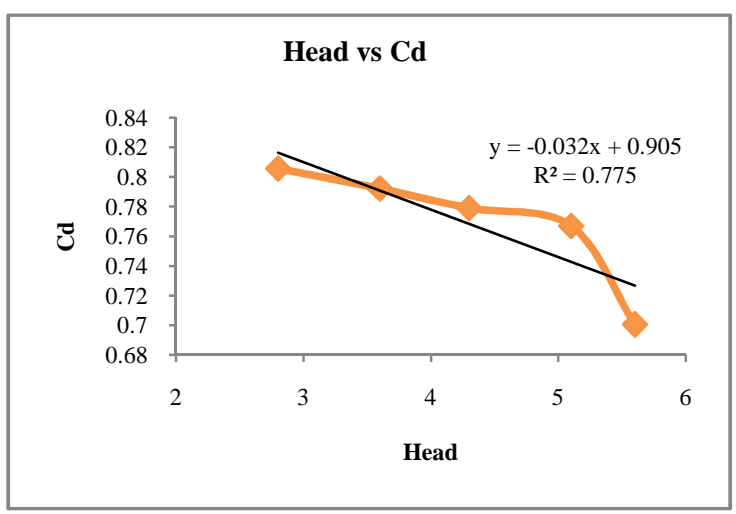

Fig 6 Variation of coefficient of discharge of V- notch with head

Fig. 6 presents the variation of coefficient of discharge with respect to head. This experiment is conducted on $\mathrm{V}$ notch $\left(60^{\circ}\right)$. It represent that the coefficient of discharge is going to fall down at the starting point of head. But as the head is simultaneously increasing by which the co efficient of discharge is decreasing uniformly. There is a point comes at which the discharge coefficient is sharply decreasing.

Table 5 Variation of $\mathrm{Cd}$ of $\mathrm{V}$-notch $\left(45^{\circ}\right)$ with the flow rate

\begin{tabular}{|c|c|c|c|c|}
\hline S.No & H & $\begin{array}{c}Q_{\mathrm{A}} \\
\left(\text { in } 10^{-4}\right)\end{array}$ & $\begin{array}{c}\mathbf{Q}_{\mathrm{T}} \\
\left(\text { in } 10^{-4}\right)\end{array}$ & $\mathbf{C}_{\mathrm{d}}$ \\
\hline 1 & 5.9 & 5.24 & 8.27 & .63 \\
\hline 2 & 5.4 & 4.24 & 6.63 & .64 \\
\hline 3 & 4.5 & 2.72 & 4.20 & .64 \\
\hline 4 & 3.8 & 1.80 & 2.75 & .65 \\
\hline 5 & 3.6 & 1.66 & 2.40 & .68 \\
\hline
\end{tabular}

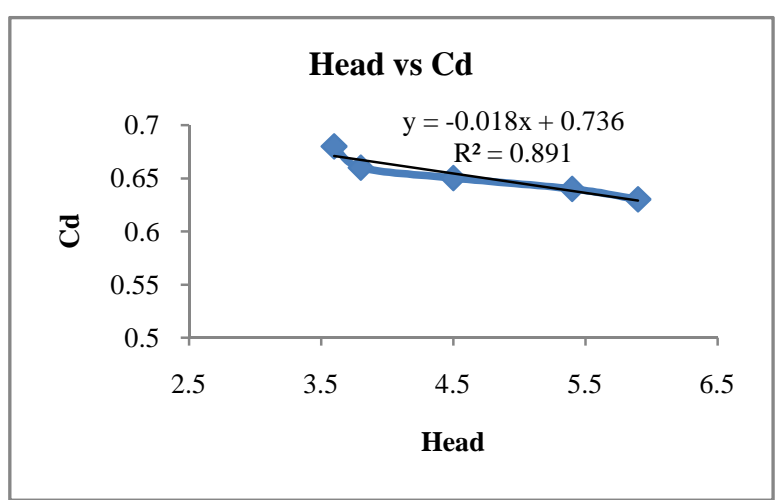

Fig 7 Variation of coefficient of discharge of of V-notch $\left(45^{\circ}\right)$ with head

Fig.7 represent the higher value of coefficient of discharge at the starting point of head but its fall down suddenly and then 
after its going to uniformly with the continuously incrementation of head discharge coefficient fall down suddenly with the minor addition of head value.

\section{Velocity Distribution in a Channel Section}

The velocity of flow at any channel section is not uniformly distributed. The non uniform distribution of velocity in an open channel is due to the presence of a free surface and the frictional resistance along the channel boundary. The velocity distribution in a channel is measured with the help of a pitot tube. The general pattern for velocity distribution as presented by lines of equal velocity. In a straight reach of a channel maximum velocity usually occurs below the free surface at a distance of 0.05 of the depth of flow. The velocity distribution in a channel section depends on the various factors such as the shape of the section, the roughness of the channel and presence of bends in the channel alignment.

The mean velocity in a channel flow section can be computed from the velocity distribution curve obtained by actual measurements. It is observed that the velocity t 0.6 depths from the free surface are very close to the mean velocity of flow in the vertical section. A still batter approximation for the mean velocity of flow is obtained by taking the average of the velocities measured at 0.2 depth and 0.8 depths from the free surface. [5]

\section{CONCLUSION}

By This experimental investigation we determine the coefficient of discharge of triangular and rectangular notches at different water levels (head). As the water level increases, the effect of viscosity and surface tension is also changes that make change in coefficient of discharge of triangle and rectangular notch. Both notches show decreases in coefficient of discharge with the increase of flow rate or depth of water.

\section{References}

1. Keshava Murthy, K., and Shesha Prakash (1996). “On the application of a new general algebraic optimisation technique to obtain the linear characteristics of a weir", ACTA Technica, Hungary, Vol. 107, No. 3-4, 265-275

2. Keshava Murthy, K., and Shesha Prakash (1994) . "Practical Constant Accuracy Linear Weir," J1. of Irrigation and Drainage Engineering Div. American Society for Civil Engineers, 120(3) , 550-562.

3. Keshava Murthy, K., and Shesha Prakash (1996). "On the dual head-discharge characteristics of a modified chimney weir", Jl. of Hydraulic Research, International Association fo r Hydraulic Research, IAHR, Vol. 31, 1996, No. 4, 502- 516.

4. Udayasimha, L., Panigrahy, B. K., and Narasimhulu, A., (2000). "Effect of crest height and width of Inverted $\mathrm{V}$ notch on Coefficient of discharge," $\mathrm{Jl}$ of Institution of Engineers (I), Vol 81(6), 101-103.

5. Modi P.N, Seth S.M. a textbook of Hydraulics and Fluid Mechanics including hydraulic machines.(2004) 705-706

6. Shesha Prakash, M.N. and Shivapur, A.V. (2004), "Generalized Head-Discharge Equation for Flow over Sharp Crested Inclined Inverted V-Notch", J1. of Irrigation and Drainage Engineering Div. American Society for Civil Engineers, Vol. 130 (4), Aug. 2004, pp 325-330.

7. Michael Robinson, Robert Houghtalen,(2006) "Dangerous dams". Rhode Island Canoe/Kayak Association (Rhode Island).

\section{How to cite this article:}

Shubham Sharma and Shalab Sharma (2017) 'Some studies on investigating the concept of determine the coefficient Of discharge for triangular \& rectangular notches with The variation of depth of water', International Journal of Current Advanced Research, 06(03), pp. 2840-2843.

DOI: http://dx.doi.org/10.24327/ijcar.2017.2843.0121 